abortion rate in the US could be due to reduced access to abortion clinics-another ideological battleground.

Three key questions should be asked about a healthcare intervention: "Can it work?" (denoting efficacy), "Does it work?" (denoting effectiveness), and "Is it worth it?" (denoting efficiency). ${ }^{9}$ For emergency contraception the first question has not been answered for obvious ethical reasons-a placebo controlled trial has never been performed. Estimates of efficacy are based on calculating the day of ovulation for individual women using emergency contraception and calculating the chance that pregnancy would have occurred by using data obtained from a cohort of women trying to conceive, who kept diaries of menses and intercourse and who had the day of ovulation determined biochemically. Many women using emergency contraception have recently had unprotected intercourse more than once, many are vague about the date of their last period, and a few were too drunk to be sure they had even had sex.

Even if emergency contraception can work (is efficacious), the experimental evidence that it does work (is effective) is disappointing. Ten studies in different countries have shown that giving women a supply of emergency contraception to keep at home, so that they have it when they need it, increases use by twofold to threefold..$^{10}$ In three studies that measured subsequent pregnancy rates, advance provision of emergency contraception increased its use but had no measurable effect on rates of pregnancy or abortion. ${ }^{10-12}$ When reasons for not using emergency contraception, despite having a supply at home, were documented three out of every four women said they did not realise they had put themselves at risk of pregnancy.

So is emergency contraception worth the fuss? If you are a woman who has had unprotected sex then of course it is, because emergency contraception will prevent pregnancy in some women some of the time- and if you don't want to get pregnant anything is better than nothing. If you are the $C M A$ /s editor or FDA commissioner then yes, because scientific freedom is worth the fight. If you are looking for an intervention that will reduce abortion rates, emergency contraception may not be the solution, and perhaps you should concentrate most on encouraging people to use contraception before or during sex, not after it.

Anna Glasier director

(anna.glasier@lpct.scot.nhs.uk)

Lothian Primary Care NHS Trust, Edinburgh EH4 1NL

Competing interests: In the past five years AG has received grants from Schering Health (which markets emergency contraception in the UK) for running educational programmes.

Hopkins Tanne J. FDA ducks decision on emergency contraceptive. BMJ 2005;331:596.

Spurgeon D. CMA draws criticism for sacking editors. BMJ 2006;332:503. 3 Emergency contraception: prudes and prejudice. Lancet 2005;366:2

4 Gordon AF, Owen P. Emergency contraception. Change in knowledge of women attending for termination of pregnancy. Br J Fam Plann 1999;24:121-2.

5 Garg M, Singh M, Mansour D. Peri-abortion contraceptive care: can we reduce the incidence of repeat abortions? J Fam Plann Reprod Health Care 2001;27:77-80.

6 Trussell J, Stewart F. The effectiveness of postcoital contraception. Fam Plann Perspect 1992;24:262-4.

Jones RK, Darroch JE, Henshaw SK. Contraceptive use among US Jones RK, Darroch JE, Henshaw SK. Contraceptive use among US
women having abortions in 2000-2001. Perspect Sex Reprod Health 2002;34:294-30

8 Tyden T, Aneblom G, von Essen L, Haggstron-Nordin E, Larsson M, Odlind V. No reduced number of abortions despite easily available emergency contraceptive pills. Studies of women's knowledge, attitudes and experience of the method. Lakartidningen 2002;99:4730-2.

9 Haynes B. Can it work? Does it work? Is it worth it? BMJ 1999;319:652-3.

$10 \mathrm{Hu}$ X, Cheng L, Hua X, Glasier A. Advanced provision of emergency contraception to postnatal women in China makes no difference to abo contraception to postnatal women in China makes no difference to abo

1 G 1 Glasier A, Fairhurst K, Wyke S, Ziebland S, Seaman P, Walker J, et al. Advanced provision of emergency contraception has not reduced abortion rates in Lothian. Contraception 2004;69:361-

12 Raine TR, Harper CC, Rocca CH, Fischer R, Padian N, Klausner JD, et al. Direct access to emergency contraception through pharmacies and effect on unintended pregnancy and STIs. A randomized controlled trial. JAMA 2005;293:54-62.

doi $10.1136 /$ bmj.38960.672998.80

\title{
Salt reduction in the United States
}

\section{Halve salt in processed and restaurant food, says American Medical Association}

$\mathrm{I}$ n June 2006, the American Medical Association catapulted its salt policy into the headlines. In a bold step the association's membership voted to implement several strategies to reduce salt intake. The members voted (a) to urge the Food and Drug Administration (FDA) to revoke the "generally recognized as safe" (GRAS) status of salt and develop regulatory measures limiting the amount of salt in processed and restaurant foods; (b) to establish quantifiable milestones, specifically a $50 \%$ reduction over the next decade, in the salt content of processed foods, fastfood products, and restaurant meals; $(c)$ to join in partnership with organisations to educate consumers about the benefits of long term salt reduction; and (d) to work with the FDA to improve food labelling and develop warning labels for foods high in salt. The association's decision to advocate salt reduction follows a recent series of reports in the United States recommending sharp reductions in salt consumption, largely because of its adverse effects on blood pressure. ${ }^{1-5}$

The response from industry was swift and predictable. Leading the charge against the proposal is the Salt
Institute, an international trade organisation of salt producers. In a news release, the Salt Institute claimed that "the American Medical Association has misread the science, confusing blood pressure effects with health outcomes." The Salt Institute, now allied with the US Chamber of Commerce, argues that policy making should rely only on evidence from clinical trials that use clinical outcomes such as stroke and mortality rather than intermediary outcomes such as blood pressure. However, blood pressure is an important, aetiologically relevant risk factor for cardiovascular and renal diseases and is widely accepted as a valid marker for policy making. ${ }^{6}$ In addition, a large scale, long term, lifestyle modification trial with clinical outcomes is unrealistic. It would not be worth the considerable time and expense because of the overwhelming evidence for salt's adverse effects on blood pressure.?

Reducing salt intake is similar to achieving other lifestyle modifications in that a substantial public health approach will be required in addition to changes in individual behaviour. The need for a public health 
approach is even greater with salt reduction than other lifestyle modifications. In contrast to cigarette smoking, where use is evident to the consumer, the salt content of our diets is not readily apparent: over $75 \%$ of consumed salt comes from processed foods. ${ }^{8}$

Hence, any meaningful strategy to reduce salt intake must involve the efforts of food manufacturers and restaurants, either voluntarily (by persuasion) or involuntarily (by regulation). The latter may be required, given the initial response of commercial bodies to the American Medical Association's proposal. The need for public health approaches is also apparent, given the global burden of hypertension (estimated worldwide prevalence of 972 million persons in $2000^{9}$ ) and the limited success of lifestyle interventions designed to reduce individuals' salt intake. Such interventions have been notoriously difficult to implement, especially in the setting of a food supply containing "hidden" salt.

In clinical trials, intensive interventions that focused just on salt reduction have shifted mean intake to about $100 \mathrm{mmol}(2.3 \mathrm{~g}$ ) of sodium (equivalent to $5.8 \mathrm{~g}$ of salt) a day. ${ }^{10-12}$ When efforts to reduce salt intake were combined with weight loss ${ }^{11}$ or as part of a comprehensive lifestyle intervention programme, ${ }^{13}$ salt reduction was more modest, probably because of the complexity of making multiple lifestyle changes and potential tradeoffs when there are several lifestyle goals.

The proposal by the American Medical Association may represent a turning point in public health efforts that have so far been largely ineffective in the US. The actions of doctors and their leadership carry enormous weight, as they did for tobacco control efforts. It is reasonable to conceive that physicians' actions have been an integral, if not essential, component of tobacco control efforts in the US, given their influence on individual patients, their communities, and healthcare policy.

Advice to reduce salt intake has been issued for about 30 years, despite persistent and highly aggressive attempts by commercial interests to weaken recommendations. With publication of the US Dietary Guidelines report ${ }^{4}$ and a subsequent "harmonisation" process, salt recommendations are now uniform and accepted by all branches of the federal government. Recommendations are also more stringent-the currently recommended upper limit of sodium intake is $100 \mathrm{mmol}$ a day in the general population and 65 mmol a day in people who are especially sensitive to the adverse effects of sodium (African-Americans, middle aged and older individuals, and people with hypertension, diabetes, or chronic kidney disease). ${ }^{4}$

The critical issue in the US, as in most other countries, is developing a comprehensive strategy to achieve meaningful, population-wide reduction in salt intake. In this setting, the association's proposal is a logical and coherent framework for accomplishing this vitally important public health objective.

Lawrence J Appel professor of medicine, epidemiology, and international health (human nutrition)

Johns Hopkins University, 2024 East Monument Street, Suite 2-618, Baltimore, MD 21205-2223 (lappel@jhmi.edu)

Competing interests: None declared.

1 Chobanian AV, Bakris GL, Black HR, Cushman WC, Green LA, Izzo JL Jr, et al. Seventh report of the Joint National Committee on Prevention, Detection, Evaluation, and Treatment of High Blood Pressure. Hypertension 2003;42:1206-52.

2 Havas S, Roccella EJ, Lenfant C. Reducing the public health burden from elevated blood pressure levels in the United States by lowering intake of dietary sodium. Am J Public Health 2004;94(1):19-22.

3 Food and Nutrition Board, Institute of Medicine. Dietary reference intakes for water, potassium, sodium, chloride, and sulfate. Washington, DC: National Academies Press, 2005

42005 Dietary Guidelines Advisory Committee Report. www.health.gov/ dietaryguidelines/dga2005/report/ (accessed 11 Sep 2006).

5 Appel LJ, Brands MW, Daniels SR, Karanja N, Elmer PJ, Sacks FM, et al. Dietary approaches to prevent and treat hypertension: a scientific statement from the American Heart Association. Hypertension 2006;47:296-308.

6 He J, Kearny PM, and Muntner P. Blood pressure and risk of vascular disease. In: Whelton PK, He J, Louis GT, eds. Lifestyle modification for the prevention and treatment of hypertension. New York: Marcel Dekker, vention and $2003: 23-51$.

7 He FJ, MacGregor GA. Effect of longer-term modest salt reduction on blood pressure. Cochrane Database Syst Rev 2004;(1):CD004937.

8 Mattes RD, Donnelly D. Relative contributions of dietary sodium sources. J Am Coll Nutr 1991;10:383-93.

9 Kearney PM, Whelton M, Reynolds K, Muntner P, Whelton PK, He J. Global burden of hypertension: analysis of worldwide data. Lancet 2005;365:217-23.

10 The effects of nonpharmacologic interventions on blood pressure of persons with high normal levels. Results of the trials of hypertension prevention, phase I. JAMA 1992;267:1213-20.

11 Effects of weight loss and sodium reduction intervention on blood pressure and hypertension incidence in overweight people with high-normal sure and hypertension incidence in overweight people with high-normal
blood pressure. The trials of hypertension prevention, phase II. The blood pressure. The trials of hypertension prevention, phase II. The
Trials of Hypertension Prevention Collaborative Research Group.

12 Whelton PK, Appel LJ, Espeland MA, Applegate WB, Ettinger WH Jr, Kostis JB, et al. Sodium reduction and weight loss in the treatment of hypertension in older persons: a randomized controlled trial of nonpharmacologic interventions in the elderly (TONE). TONE Collaborative Research Group. JAMA 1998;279:839-46.

13 Elmer PJ, Obarzanek E, Vollmer WM, Simons-Morton D, Stevens VJ, Young DR, et al. Effects of comprehensive lifestyle modification on diet, weight, physical fitness, and blood pressure control: 18-month results of a randomized trial. Ann Intern Med 2006;144:485-95.

doi 10.1136/bmj.38971.635799.AB

\title{
Non-cephalic presentation in late pregnancy
}

\author{
Best diagnosed by ultrasound at 36 weeks
}

C aesarean section rates continue to increase around the world. Although non-cephalic presentation is not the most common indication for caesarean section, it may be one of the most preventable. ${ }^{1}$ Timely diagnosis of this condition, and an attempt at external cephalic version at about 36 weeks' gestation, has been shown to safely reduce the need for caesarean section. ${ }^{1-3}$ However, timely and efficient diagnosis of fetal malpresentation requires a screening test with a high sensitivity and high specificity.
In this issue of the $B M J$ Nassar and colleagues report a cross sectional study of the diagnostic accuracy of clinical examination for the detection of non-cephalic presentation in late pregnancy. ${ }^{4}$ Their findings are worrying: non-cephalic presentation was correctly diagnosed in only $70 \%(91 / 130)$ of cases and in only $38 \%$ of obese women $(3 / 8)$. The authors correctly point out that missing the diagnosis of non-cephalic presentation precludes the ability to offer external cephalic version and increases the likelihood

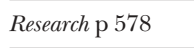

BMJ 2006;333:562-3 